Feeney, Mary K. and P. Craig Boardman. forthcoming. Organizational confidence: An empirical assessment of highly positive public managers. Journal of Public Administration Research \& Theory. (2010) doi: 10.1093/jopart/muq044

\title{
Organizational confidence: An empirical assessment of highly positive public managers
}

\author{
Abstract \\ There is a great deal of research investigating public servants’ perceptions of \\ organizational problems (e.g. red tape, bureaucratic control); however, there is little \\ research investigating public servants who have highly positive perceptions of their \\ organizations. This paper assesses perceptions of state employees to investigate \\ individual and organizational level correlates with highly positive government workers, \\ which we define as workers reporting high levels of pride in the organization for which \\ they work, and who believe that the organization provides high quality public services \\ and operates by highly ethical standards. Using data from the National Administration \\ Studies Project III, we draw from formal theories of worker attitude formation and \\ change to frame our assessment of these ideal-type public managers in terms of \\ contemporaneous perceptions of work and work environment, structural job \\ characteristics, and career trajectory. We conclude with a discussion of the implications \\ for public management and policy.
}




\section{Organizational confidence: An empirical assessment of highly positive public managers}

\section{Introduction}

Committing one's career to public service carries with it the ideal of the committed public servant who believes in her organization and who believes that her organization can and does “make a difference.” However, empirical study of public sector workers paints a somewhat different portrait - one of workers who are dissatisfied with their organizations due to, for example, “red tape,” among numerous other factors, but who no less report high levels of public service motivation (Perry 1996; Perry and Wise 1990). Though public sector workers may be highly motivated to serve, on average they seem less than enamored with the government organizations for which they work.

While it may be reasonable to expect somewhat negative worker perceptions of and attitudes towards government organizations, intuition suggests that the consistency of findings in this regard is a function of the organizational pathologies and management challenges that have motivated much of the empirical research on public sector workers (Rainey 2003). In contrast, our study focuses on a subset of public managers who believe strongly that their organizations “make a difference," specifically on managers who report high levels of pride in their organizations and concomitantly that their organizations provide high quality public services and have high ethical standards.

We focus on these individuals because, from a management perspective, they represent the ideal insofar that such highly positive workers perhaps reduce the most 
fundamental challenge of organizations and may be relatively easy to induce to work towards organizational goals and public service missions (Simon 1997). Moreover, understanding this subset of public sector workers may be insightful in terms of personnel selection and retention, a consistent challenge (if not a contemporaneous one, given the current economic downturn) for government organizations (Light 1999). Because workers may be attracted to government by the motivation to serve the public good or perhaps because of a specific agency's mission, the perception of the provision of high quality and ethical public service may be essential to ensuring that government workers have pride in and are retained by public organizations (Schneider 1987, Schneider et al. 1995, Wright and Pandey 2009).

So how do public sector organizations go about populating their ranks with workers who harbor such positive attitudes and perceptions? Perhaps there is nothing for organizations to do - such attitudes and perceptions could be the inevitable result of the effective provision of public service (Boardman and Sundquist 2009) or self-selection and attrition (Schneider 1987; Schneider et al. 1995). In this case, public sector organizations simply need to be effective at service provision to elicit highly positive worker attitudes and perceptions. Yet, workers bring to their jobs unique reference points based on their past work experiences (Light 1999), current job responsibilities, and individual characteristics and personalities that result in variable perceptions of and attitudes towards the same organization (Feeney 2008). Just as the structural features of organizations are perceived and interpreted differently by different workers, based on individual professional and personal characteristics (Ponomariov and Boardman, 
forthcoming), so too may perceptions of an organization’s public service quality and ethicalness be contingent on individual-level factors.

Government organizations, no matter how effectively and ethically they provide public services, cannot be entirely assured of highly positive worker perceptions and attitudes. Some workers will be more likely than others to develop pride in their organizations and to perceive them as effective and ethical, even if their organizations have room for improvement in these areas. This is not to say that high quality public service and ethical standards do not matter to the development of highly positive worker attitudes and perceptions (these certainly matter), but rather that workers who are highly positive may be so due to a number of individual-level factors about which very little is known - due to the limited attention highly positive workers have received in the literature.

In this research, we aim to understand what individual-level characteristics correlate with highly positive worker perceptions of and attitudes towards government organizations. First, feeling high levels of pride in one's organization and perceiving it to be both highly effective and operating by ethical standards is a multidimensional concept - one difficult to capture with any single attitude or perception. Second, highly positive worker attitudes and perceptions may be linked not just to workaday contextual factors and contemporaneous attitudes and perspectives, but to past work experiences and prior beliefs that help to form current beliefs and motivations (Azjen 2000) - thus requiring historical as well as current data on workers' careers, attitudes, and perceptions, at multiple levels of analysis. Despite such challenges, this is an area of research worthy of persistent (if imperfect) inquiry, given the centrality of workers' beliefs that they are 
performing meaningful work to the achievement of long-term organizational goals (Pfeffer 1998).

In response to the first challenge - capturing the multidimensionality of the highly positive government worker - we employ a scale drawing conceptually from two distinct perspectives: worker-organization "fit” emphasizing worker perceptions of particular attributes in the organization and organizational commitment emphasizing worker affectation for the organization. For the latter, our scale measures the extent to which public sector workers have high levels of pride in their organizations. For perceptions of particular organizational attributes, our scale measures individual reports of high quality public service provision and high ethical standards. We name the scale "organizational confidence.” While this concept has some overlap with related concepts, it is a new scale based on existing ideas, which for the purpose of this study the approach is most appropriate. The notion of the highly positive public sector worker is not a singular concept, but one that encompasses numerous dimensions related to worker affectations and perceptions.

In response to the second challenge of studying the highly positive government worker - accounting for the numerous factors that correlate with worker attitudes and perceptions, highly positive and otherwise - we employ an explanatory framework that includes contemporaneous and historical, organization-level and individual-level, and cognitive and non-cognitive factors deemed important for developing an understanding of the social psychology of work (Fishbein and Middlestadt 1995; Petty and Krosnick 1995). Specifically, we address workaday behaviors, past career experiences, perceptions 
of organizational context, personal attitudes and motivations, and contextual factors such as organizational type, size, and age. We test the framework using data on public sector managers from the most recent National Administrative Studies Project (NASP-III), a survey of public managers in Georgia and Illinois. ${ }^{1}$

\section{Organizational confidence}

Although a great deal of empirical research characterizes public sector workers as having negative attitudes towards work and work environment, a recent exception is Charles Goodsell's work (2004) arguing that individuals who devote their lives to public service in the United States are highly competent assets to our society and democracy, providing vital services and ensuring the public interest. Although public administration researchers and practitioners are well-versed in Goodsell's work, researchers interested in the perceptions and attitudes of public sector workers continue to focus on the darker sides of public management including bureaucratic personalities (Bozeman and Rainey 1998; Merton 1940; Wilson 1989), red tape (see the work of Pandey and Bozeman), excessive power and oppression of individuals (Sjoberg et al. 1966), and inefficiencies and poor performance (Behn 2001; Niskanen 1973) - with public service motivation and public values research offering exceptions to this rule.

Moving forward from Goodsell’s contention that many public servants are driven by a general desire to serve the public and to advance organizational missions, we focus on positive perceptions of public organizations from within - specifically on individuals working in government who report high levels of pride in their organizations and who

1 The survey was administered to managers and technicians and professionals in managerial positions. For simplicity, we refer to the respondents as managers. 
believe that their organizations have high ethical standards and provide high-quality public services. This focus is part of an emerging literature highlighting the importance of government employees’ positive perceptions of government. For example, Jensen (1998) emphasizes the importance of "strong tastes" among government workers for organizational outputs and Rainey and Steinbauer (1999) argue an organization's mission to be an important source of work motivation. Wright (2001) relates government workers' organizational commitment to positive perceptions of organizational goals. Most recently, Boardman and Sundquist (2009) show a relationship between government workers’ perceptions of "public service efficacy" and individual levels of commitment and satisfaction. These recent studies all draw from Buchanan’s (1974) proposition that the "attractiveness" to workers of their public organizations declines if the organizations do not operate well and produce results.

What we term "organizational confidence" is a scale comprised of responses to the following three NASP-III survey items: "This organization has high ethical standards," "I would rate the overall quality of work being done in my organization as very good," and "I feel a sense of pride working for this organization." The scale is uniquely focused on both positive perceptions of and positive affectation for one's organization. The scale addresses both perceptions and affectation due to the multidimensionality of the concept of the highly positive government worker.

The organizational confidence scale items for worker perceptions of the provision of high quality public services and of high ethical standards in the organization, while original to this study, draw from research and theory on worker-organization value 
congruence emphasizing individual workers' perceptions of particular attributes in their organizations (Amos and Weathington 2008). Thematically, these two scale items are similar to those used for the "needs-supplies” conceptualization of worker-organization fit, which occurs when an organization satisfies individual workers’ preferences (e.g., Kristof 1996). For instance, some of the worker preferences emphasized in this body of work include individual perceptions of "superior quality and service" and "importance of details of execution” in the organization (Amos and Weathington 2008). An important difference is that our items by design do not directly address the notion of congruence or fit between workers and organizations, but rather the worker's perceptions of the organization.

The organizational confidence scale item for feeling a sense of pride in one's organization does address the idea of fit or congruence between organizational and worker values. The item is quite similar to certain operationalizations of affective organizational commitment, including those using Porter's original questionnaire item for organizational pride (Porter et al. 1974). We included the item in the scale because the coincidence of such a positive affectation for one's organization with perceptions of organizational attributes like high ethical standards and high quality service provision strongly suggests that one who perceives these attributes in one's organization also values them. Moreover, that high quality and ethical government services can greatly increase operational costs in government (depending on the activity, see Dougherty 2000) suggests that organizations operating at a level to elicit such positive worker affectations and perceptions value these aspects as well. 
Though naming the scale "organizational confidence" implies the introduction of a new concept, we acknowledge that the discrete dimensions used for the scale are not entirely original. However, we believe the combination of both affective and perceptual dimensions to be novel. Whereas organizational commitment items typically employ the individual worker as referent - which is appropriate given the general purpose to characterize an individual's sense of devotion to an organization (Cohen 2007) - some conceptualizations of organization-worker value congruence employ the organization as referent - which is appropriate given the approach's emphasis on fit. To adequately address highly positive public sector workers, consideration of both personal affectation towards and individual perceptions of the organization is required. In this sense, the organizational confidence scale uses existing items and approaches in a new way to account for the multidimensionality of the highly positive government worker. ${ }^{2}$

The combination of concepts represented by the organizational confidence scale proves beneficial theoretically as well as operationally. The framework and hypotheses articulated in the next section draw on literatures addressing correlates with positive worker affectations for and perceptions of organizations. In addition to the literatures on worker-organization congruence and organizational commitment which are useful in terms of specifying potential correlates, we draw from broader theories of attitude

2 We acknowledge that a three-item scale may not go far in terms of capturing multiple dimensions. However, the organizational confidence concept is exploratory - i.e., by combining individual-level affective commitment and perceptual dimensions related to one's work organization. Moreover, the quantity of items does not necessarily dictate the validity of the scale. For example, the Meyer and Allen (1984) three-item scale for organizational commitment has been shown to have better fit scores than organizational commitment scales using more than three items from Porter's Organizational Commitment Questionnaire (Cohen 1996). Similar, single item measures of job satisfaction have been shown to be as valid as multi-item scales (Nagy 2002). 
formation and change to frame our expectations regarding the highly positive government worker.

\section{Hypotheses}

Most prior studies of public managers take a social psychological approach to understanding cognitive and affective outcomes like organizational confidence, emphasizing personal characteristics including individual perceptions of and attitudes towards work and work environment. While these factors are fundamental to developing an understanding of the government workers, highly positive and otherwise, historical factors, including an individual's past work experiences, as well as non-cognitive factors, such as attributes of past and current organizations and jobs are important for understanding social psychological outcomes. ${ }^{3}$ Due to data limitations, most work in public administration seems to presume that work-related perceptions and affectations emerge as products of current beliefs and immediate contexts. However, empirical tests of the effects of past work experiences and current job and organizational characteristics are gaining consideration in more recent public administration scholarship (Boardman et al. 2010; Feeney 2008; de Graaf and Van der Wal 2008).

Accordingly, the framework for this study accounts for both contemporaneous and historical as well as cognitive and non-cognitive factors to assess individual and organizational correlates of the highly positive government worker. ${ }^{4}$ While these broad

3 The consideration of these additional factors has decades of empirical and theoretical precedent in applied and occupational psychology (for a review of the literature, see Azjen 2000).

4 The variables included in the framework exclude those that are simultaneously historical and cognitive (e.g., one's level of public service motivation during a previous job) because the NASP III dataset used for this study excludes such measures, due the validity problems associated with them. But the NASP III dataset includes variables that are historical and non-cognitive (e.g., past work experience in a firm), contemporaneous and non-cognitive (e.g., current job responsibilities), and of course many of the contemporaneous and cognitive variables included in much public administration research on public managers' work attitudes and perceptions (e.g., public service motivation during the current job, job 10 
categories encourage comprehensiveness, past research and theory for the concepts used to conceptualize organizational confidence - specifically research and theory for workerorganization fit and organizational commitment - facilitate parsimony. Though our framework helps us to categorize organizational and individual attributes that may correlate with highly positive perceptions of and affectations for one's organization, these literatures help to identify specific variables for each category. Specifically, we use the following categories of explanatory variables: work motivation, perceptions of the current work environment, past work experience, and worker behavior and outcomes. We discuss the rationale for each below.

Work motivation. For work motivation, we are concerned with the relationship between a desire to serve the public interest and organizational confidence. The rationale for this focus is that some studies demonstrate a link between positive perceptions of and attitudes towards work and work environment and high reported levels of a desire to engage in public service. For example, Brehm and Gates (1999) demonstrate the importance of non-pecuniary rewards to workers at the Federal, state, and "street” levels whereby government workers report feeling rewarded "by performing the very things" that they are supposed to do (p. 75). Naff and Crum (1999) show that public service motivation (PSM) among federal workers is correlated positively with job satisfaction and the intent to remain in the current job. Crewson (1997) and Taylor (2008) show a similar relationship between PSM and organizational commitment, which is one of the dimensions of organizational confidence. Park and Rainey (2007) show a positive

satisfaction). 
relationship between affective commitment, which can include the scale item we use for having a sense of pride in one's organization, and "public service-oriented motivation."

There is also reason to expect a correlation between organizational confidence and a desire to serve the public based on studies of worker-organization fit (Alonso and Lewis 2001; Brewer and Selden 1998; Perry and Wise 1990; Taylor 2008), which are related to the dimensions of our scale for perceptions of high ethical standards and high quality public service provision by one’s organization. For example, Wright and Pandey (2009) find that workers who report high levels of PSM are more likely to be satisfied with their jobs when their respective personal values are congruent with those of the government organizations for which they work. Moreover, workers with "high social values," such as a concern for others, have been shown to perceive congruence or fit with their organizations, and to view their organizations positively (Meglino et al. 1989, Dewitt et al. 2003, Jansen and Kristof-Brown 2006).

Thus, if there is a link between a desire to serve the public and the highly positive government worker, it may be that individuals motivated to work in the public interest would be more likely to view their organizations in a highly positive light:

H1: An increased desire to serve the public will be positively associated with organizational confidence.

We expect that organizational confidence, or being highly positive about one's organization, will be reflected in the discrete personal values that are perceived to be fulfilled by one’s public employer (e.g., taking pride in the organization when it provides high quality public service and operates by high ethical standards). 
Perceptions of current work environment. We are concerned with the relationship between organizational confidence and perceptions of organizational rules and procedures as burdensome "red tape" in the workplace as well as with perceptions of client satisfaction. We include the former due to consistent findings of the negative emotive and attitudinal results of perceived red tape. For example, research indicates that perceived red tape is correlated with feelings of worker alienation (Bozeman and Rainey 1998; DeHart-Davis and Pandey 2005; Pandey and Welch 2005), which in turn may have a negative impact on work motivation (Pandey and Kingsley 2000). Using structural equations, Pandey and Welch (2005) show that worker alienation, perceived red tape, and administrative delay are interrelated. Previous research also shows that perceived red tape is related to perceived organizational performance (Brewer and Walker 2009; Pandey et al. 2007), organizational culture (Pandey et al. 2007), and bureaucratic behavior (Scott and Pandey 2000). We expect that red tape perceptions will be negatively related to organizational confidence.

H2: Increased perceptions of organizational red tape will be negatively associated with organizational confidence.

As a multidimensional construct for highly positive attitudes toward and perceptions of one's organization, organizational confidence may decline as negative perceptions of work and work environment, including but not limited to perceptions of red tape, increase. While other negative perceptions of the organization could also be included in our analysis, we focus on perceptions of red tape due to its salience as a negative perception of public sector organizations. 
We test the relationship between a positive perception of work environment and organizational confidence to provide discriminant validity. Specifically, the framework includes the perception of client satisfaction because we expect that the respondent's perception that clientele are satisfied with the services provided by the organization can weigh heavily on the respondent's level of organizational confidence. In fact, this seems an important perceptual variable absent from many studies of workers’ attitudes towards and perceptions of their organizations.

H3: Increases in perceived client satisfaction will be positively associated with organizational confidence.

Thus as a multidimensional construct for highly positive affectation for and perceptions of one's organization, organizational confidence may increase as positive perceptions of work and work environment, including but not limited to perceptions of client satisfaction, increase. While other positive perceptions of the organization could also be included, we focus on client satisfaction due to its relevance to the dimensions of the organizational confidence scale. Along this line, the item helps to indirectly account for variability across respondents’ organizations in terms of organizational quality and ethicalness.

Past work experience. Past work experience has been shown to affect some of the dimensions of organizational confidence, including measures of worker-organization fit (Kristof-Brown et al. 2002). Though there has not been study of the relationship between past work experiences and affective commitment, Boardman and colleagues (2010) shows that past work experience is related to the job involvement of public managers, which has long been found to correlate positively with commitment (e.g., 
Buchanan 1974). Specifically, we are concerned with how career trajectories and the different experiential reference points these pose for workers correlate with the highly positive government worker, i.e. the respondent who scores very highly on the organizational confidence scale. ${ }^{5}$

The rationale for the focus on private sector work experience is that the norms, expectations, and experiences of the private sector are in many ways different than those of the public sector (Eggleston and Zeckhauser 2002; Perry and Rainey 1988; Rainey 1982, 1983). For example, research finds that public organizations have higher levels of centralization and formalization compared to private firms (Bretschneider 1990; Marsden et al. 1994). Similarly, research finds that public sector employees are more public service-minded (Rotolo and Wilson 2006) and place greater importance on personal relations (Rawls et al. 1975) than their private sector counterparts. Government workers can have different reference points from which to develop attitudes towards and perceptions of their current work environs, tasks, and responsibilities, and previous experience in a different sector can influence current perceptions (Azjen 2000; Boardman et al. 2010; Feeney 2008; de Graaf and Van der Wal 2008).

We suggest that public managers who transitioned to their current jobs from the private sector were highly motivated to do so. Of course, sector switching can occur in both directions. First, workers might depart from the public sector to the private sector due to wage differentials and the desire for less bureaucratic work (Light 1999; SousaPoza and Henneberger 2004). On the other hand, the transition to the public sector from

5 In the results below, we refer to respondents who indicated that they "strongly agree" with all three items in the organizational confidence scale as having High Organizational Confidence. 
private companies could be due to promotion or to intrinsic motivations and mission valence (Crewson 1997; Perry 1996; Perry and Wise 1990). Accordingly, we expect a positive relationship.

H4: Respondents that report previous work experience in the private sector, compared to those who have not worked in the private sector, will report increased organizational confidence.

This reasoning may be more relevant to those who worked in the private sector relatively recently when compared to public servants who worked in the private sector many jobs ago. For instance, those with more immediate work experiences in the private sector may perceive their current public organization’s performance less critically than workers who too have worked in the private sector, but more than one job ago. Thus, we include measures for having a private sector job anytime in the past and for the most immediate previous job being in the private sector.

Worker behaviors and outcomes. Finally, we are interested in how current work behavior relates to workers' perceptions of and attitudes towards organizations and organizational confidence. Specifically, we are concerned with the impact of absenteeism. We include this measure due to numerous studies linking days of work missed to worker perceptions and attitudes (Steers and Rhodes 1978; Spencer and Steers 1980; Vandenheuvel 1994). Negative attitudes towards work may increase absenteeism (Steers and Rhodes 1978; Spencer and Steers 1980) and absence from the workplace may limit the degree to which individuals become socialized into the workplace (Wooden 1992), also limiting the opportunity to observe the nature and quality of the public service that the organization may be providing. 
H5: Increased absenteeism will be negatively associated with organizational confidence.

While we expect that organizational confidence will decrease as absenteeism increases, it may be the case that some employees use annual leave to cover sickness, medical appointments, and so forth, and thus are not necessarily less likely to report highly positive organizational confidence. Research indicates that worker absenteeism is predominantly a function of two factors: the motivation to attend work and the ability to attend work. Operationally we do not distinguish between what researchers (Steers and Rhodes 1978, 1984) call “Type B” (absenteeism due to a lack of motivation) and “Type B” (absenteeism due to an inability to attend work). We use this measure of all leave, both voluntary (vacation and personal leave) and non-voluntary (sick leave), because researchers note that workers often use sick leave entitlements for reasons beyond illness and injury (Brooke and Price 1989; VandenHeuvel 1993, 1994; Wooden 1990). In sum, the more work that one misses, perhaps the less evidence one will have to support highly positive perceptions of and affectation for one's organization. While other behaviors could also be included, we focus on absenteeism due to its salience in studies of worker outcomes as a correlate with negative worker attitudes towards and perceptions of work and the work environment.

\section{Methods and Data}

This research uses data from the NASP-III questionnaire, a survey administered to a sample of 2,000 public managers in Georgia and Illinois. Five respondents were removed because they had retired and were ineligible. Of the remaining 1995 surveys, 145 were returned due to bad addresses. The survey was closed in January 2006 with an 
overall response rate of $43 \%$ (790 respondents). While this response rate is not ideal, the sample size is typical for privately initiated and voluntary surveys of employees especially considering that this survey was not promoted by employers, state government, or organization leaders - and remains higher than average response rates in general surveys of organizational employees (Kanuk and Berenson 1975). Typically, public sector recipients respond at higher rates than those in private organizations and the response rate is higher than comparative private sector surveys. Because the sample was drawn from a population of named contacts, we do know some information about non-respondents including the employing organization, state, job title, and in most cases the sex. The respondents do not significantly vary from the eligible non-respondents along these characteristics.

The data are limited because they are derived from a single, one-time survey. They are neither panel nor longitudinal data, making causal claims impossible. The data are primarily perceptual and could be biased by respondent mood at the time of taking the survey. Details about the NASP-III study can be found in Appendix 1.

We use an OLS and a logit model to test our hypotheses. First, we ran an OLS regression on the continuous dependent variable organizational confidence, which is the extracted scores from a factor analysis of responses to the following three survey items: (1) I feel a sense of pride working for this organization; (2) This organization has high ethical standards; and (3) I would rate the overall quality of work being done in my organization as very good (response categories: strongly agree, somewhat agree, somewhat disagree, strongly disagree). Table 1 reports the results of the factor analysis of the organizational confidence scale items. The scale reliability test, presented in table 2 , 
indicates that the scale has a Cronbach's Alpha of .821, which is well above the average cut-off for scale reliability in the social sciences. Second, because we are particularly interested in respondents who report high organizational confidence, we created a binary dependent variable for High Organizational Confidence. High Organizational Confidence is coded one if the respondent reported "strongly agree" to all three survey items and the variable is coded zero for all those who did not report strong agreement for all three items. The mean for High Organizational Confidence is .2, indicating that 161 respondents to the survey (or 21\%) have High Organizational Confidence. This binary model enables us to investigate the determinants of high organizational confidence among public sector employees.

We demarcate highly positive government workers from all other survey respondents as those who indicate that they "strongly agree" with the three survey items included in the organizational confidence scale. These public sector workers demonstrate both highly positive affectations for and positive perceptions of their organizations, which is not a necessary combination. An emotional sense of obligation towards or attachment to one's organization, such as feelings of pride, does not necessitate positive perceptions of the organization's processes and outputs. One may have positive perceptions of an organization without feeling committed, just as it is possible to feel a sense of obligation regardless of organizational performance. Two of the three items used in the organizational scale, in their specific forms, are indeed new to the literature and are focused on perceptions of organizational effectiveness and ethicalness. The last item 
originates from an oft-used organizational commitment scale. The organizational confidence scale is discussed at length in the next section.

[Insert tables 1 and 2 about here]

Independent Variables. In this section we present the independent variables in order of the hypotheses and the control variables. Descriptive statistics and a correlation matrix are listed in Appendix 2 and 3, respectively.

Desire to serve the Public is a binary variable indicating whether or not the respondent reports that the "Ability to serve the public and the public interest” was an important factor for accepting the current position (1=somewhat important/very important, $0=$ somewhat unimportant/not important). This measure is an individual-level contemporaneous measure of the cognitive (personal attitudes) of the respondent.

Red Tape is a general scale of organizational red tape, which captures the respondent's contemporaneous, cognitive perceptions of the organization. Respondents were asked: "If red tape is defined as 'burdensome administrative rules and procedures that have negative effects on the organization's effectiveness,' how would you assess the level of red tape in your organization? Please circle the appropriate response between 0 indicating 'Almost No Red Tape’ and 10 indicating 'Great Deal of Red Tape.’” This scale is common to red tape research (DeHart-Davis 2008; Feeney and Rainey 2009; Welch and Pandey 2007). Red Tape has a mean of 6.03 and a standard deviation of 2.683.

Client Satisfaction, a second contemporaneous cognitive measure of perceptions of the organization, is a variable measuring agreement with the following statement "Our clients seem quite satisfied with the performance of this organization” (1=strongly disagree; 2=somewhat disagree, 3=somewhat agree, 4=strongly agree). 
Private is a dummy variable indicating that one of the respondent's previous positions was in the private sector $(1=$ one of previous jobs in private sector, $0=$ no previous jobs in private sector). Private_Public is a dummy variable coded one if the respondent's current job was a switch from the private to the public sector. These two measures are historic, non-cognitive measures.

Absenteeism indicates the sum of days the respondent missed work in the previous year. Respondents were instructed “Thinking about the last 12 months, please estimate how many days of work you missed because: you were sick, your spouse or partner was sick, someone else in your household was sick, you were on vacation, you took personal leave (e.g. dentist appointment), and you were not sick or on vacation, but you could not face working.” Because we find no significant differences between the types of absenteeism reported by NASP-III respondents, we retain the summative measure for this model. Absenteeism is the sum of days indicated in response to the six items. We use this measure of all leave, both voluntary (vacation and personal leave) and non-voluntary (sick leave), because workers often use sick leave entitlements for reasons other than illness (Brooke and Price 1989; VandenHeuvel 1993, 1994; Wooden 1990).

Control variables. The variables Security Motivation and Career Advancement Motivation, both cognitive measures, indicate the respondent's reasons for taking the current position. NASP-III asked respondents to respond to the following directive, "We are interested in the factors that motivated you to accept a job at your current organization. Please indicate the extent to which the factors below (some personal, some family, and some professional) were important in making your decision to take a job at 
your current organization.” Security Motivation and Career Advancement Motivation are saved factor scores from a factor analysis using an orthogonal solution, Varimax rotation of the following six items: Opportunity for advancement within the organization's hierarchy; Job Security; The organization's pension or retirement plan; Desire for increased responsibility; Benefits (medical, insurance); and Few, if any, alternative job offers (Response options were a four point Likert scale: very important, somewhat important, somewhat unimportant, and not at all important). The factor analysis resulted in two dimensions: security and advancement, which represent $61 \%$ of the common variance in the initial correlation matrix. Table 3 presents the factor loadings matrix. The motivation measures help to capture the relationship between personality and work behavior.

[Insert table 3 about here]

The variable \#EmployeesSupervised is a categorical variable indicating the selfreported number of employees supervised, if any, with the following categories: zero employees supervised, 1-5, 6-10, 11-20, and more than 21 employees supervised. ${ }^{6}$ This variable serves to control for the respondent's role in the organization and serves as a non-cognitive control. Additionally, given the importance of context in explaining workplace perceptions and attitudes, our framework includes two organization-level noncognitive controls: organization age and size. Org Age is a continuous variable. ${ }^{7}$ Org FTE

6 Responses to the number of employees supervised were skewed, ranging from zero to 1200, with the highest quintiles starting at less than 100 . We created an ordinal variable with the following categories: zero employees supervised, 1-5, 6-10, 11-20, and more than 21 employees supervised.

7 We were unable to determine the organizational age of six agencies, which resulted in missing data for 67 individuals. Because we wanted to ensure that these individuals were not dropped from the analysis, we inputted the mean organizational age (56.89 years) for these 67 missing cases. We were also unable to accurately gauge organizational size for seven agencies, or 38 individuals. In the case of number of full time employees, we inputted the median number of 2007, since the range was from 11 to 18700 with a mean of 5220 and a standard deviation of 6316 . We ran all of the analyses with the original variable and 22 
is a continuous variable indicating the number of full time employees working at the respondent's organization. The dummy variable Georgia is coded one if the respondent works in Georgia. Because the relationship between age and perceptions is not linear; we include the controls Age and Age Squared so that the regression model better fits the data.

\section{Models and Results}

Because we are primarily interested in respondents who reported High Organizational Confidence (strongly agree with all three items in the scale), we begin with a comparison of public managers who report High Organizational Confidence and respondents who did not. We then present findings for the OLS regression and logit analyses.

Table 4 shows the results from a comparison of means for public managers who report High Organizational Confidence and those who do not. Respondents who report High Organizational Confidence report significantly more desire to serve the public and the public interest, higher perceptions of client satisfaction, and increased red tape in their organizations. Being employed in Georgia, as compared to Illinois, is also significantly related to reporting High Organizational Confidence. Respondents from Georgia are significantly more likely to report High Organizational Confidence, compared to those working in Illinois. Finally, respondents who work in older organizations are more likely to report High Organizational Confidence than those in younger public agencies. It makes sense that High Organizational Confidence would be positively and significantly related to working in an organization that has been serving the public for a longer time, since that

with the computed missing values. Using the variables with inputted missing values increased the $\mathrm{N}$, but did not significantly alter the sign, significance, or magnitude of the beta coefficients. 
organization might be more stable, have a strong culture for mission attainment, and engender confidence in its employees. The difference of means tests, comparing public managers with High Organizational Confidence and those who do not report High Organizational Confidence demonstrates the importance of retaining two models to investigate the relationships between the independent variables and organizational confidence (as a factor) and the binary measure of High Organizational Confidence. We address the hypotheses in our discussion of the regression results below.

[Insert table 4 here]

We present the results of our OLS regression model (see table 5) and logit model (see table 6) in the order of the hypotheses. We then discuss the relationships presented in the analysis. Table 5 shows the results from the OLS model predicting the saved factor scores for organizational confidence. The model is significant $(\mathrm{P}<.001)$ and has an adjusted R squared of .383, indicating that the independent variables in the model predict approximately $38 \%$ of the variation in organizational confidence. The logit model predicting High Organizational Confidence is presented in table 6. The model fit statistics indicate that the model is significant at the $\mathrm{P}<.000$ level. In both the OLS and logit models we find that a desire to serve the public, perceived client satisfaction, increase career advancement motivation, an increase in the number of employees supervised, and working in Georgia are positively associated with increased organizational confidence or reporting High Organizational Confidence. In both models, increased perceptions of red tape are significantly, negatively related to organizational confidence.

[Insert tables 5 and 6 about here] 
First, the results demonstrate support for hypothesis 1 - that a desire to serve the public is positively associated with organizational confidence. The OLS model predicting the saved factors scores indicates that there is a significant $(\mathrm{p}<.01)$ positive relationship between a desire to serve the public and the public interest and organizational confidence. The logit model indicates that the odds that a public manager will report High Organizational Confidence are 1.12 times higher for those who report a strong desire to serve the public and the public interest compared to public managers who do not report this desire. Thus the desire to serve the public interest is significantly related to organizational confidence.

The second hypothesis predicted a negative relationship between the perception of organizational rules and procedures as red tape and organizational confidence. Both the OLS model and the binary logit models indicate strong significant support for hypothesis $2(\mathrm{p}<.01)$. Public managers who report that their organization has high levels of red tape are less likely to report High Organizational Confidence. All else being equal, a one-point increase on the scale of perceived organizational red tape is related to a reduction in the odds that a respondent reports high organizational confidence by a factor of .780.

The results also support the third hypothesis - that perceived client satisfaction is positively associated with increased organizational confidence. Respondents who perceive that "Our clients seem quite satisfied with the performance of this organization" report significantly higher organizational confidence than those who do not report client satisfaction. The odds that a respondent who reports that clients are satisfied will report 
High Organizational Confidence is estimated to be 0.606 times higher than those who do not report client satisfaction.

Hypothesis 4 suggests that respondents who report previous work experience in the private sector (compared to those who have not worked in the private sector) will be more likely to report increased organizational confidence. The OLS model indicates that there is not a significant relationship between private sector work experience and organizational confidence. The logit model investigating High Organizational Confidence also indicates that there is not a significant relationship between previous private sector work experience and High Organizational Confidence. We also find no relationship between organizational confidence and respondents whose previous position was in the private sector. It is possible that these measures do not capture the true effects of private sector work experience, since the respondent's private sector work experience may have occurred many jobs ago.

While the OLS model predicting the organizational confidence scale indicates no support for hypothesis 5 , the logit model finds a significant relationship between absenteeism and High Organizational Confidence. Absenteeism is negatively related to High Organizational Confidence. Respondents who report increased absenteeism are significantly less likely to report High Organizational Confidence - reporting pride in the organization and strongly agreeing that the organization is ethical and provides high quality public services. All else equal, the odds that a respondent reports High Organizational Confidence are .98 times lower with each day of work missed. Thus we see that absenteeism is not related to small changes in organizational confidence (the 
OLS model predicting the saved factors scores) but is negatively related to reporting high levels of organizational confidence.

Finally, in both the OLS and the logit models we see that working in Georgia, as compared to Illinois, is significantly related to reporting increased organizational confidence. The odds that a public manager in Georgia will report High Organizational Confidence are 1.2 times higher than the odds that a public manager in Illinois will report High Organizational Confidence. These relationships may be explained by cultural distinctions between states in two regions: the south and the Midwest. On the other hand, these relationships may be shaped by the strong presence of unions in Illinois and the absence of unions in Georgia. A third explanation may be the extensive civil service reforms in Georgia (Kellough and Nigro 2006; Nigro and Kellough 2000).

\section{Discussion and Conclusions}

This analysis focuses on investigating public managers' with highly positive perceptions of their organizations, measured as organizational confidence. Organizational confidence is a multidimensional concept that captures pride in and perceptions of quality of service and ethicalness of operations in one's organization. With a sample of public employees working in state government, we identify individual-level factors including work motivation (e.g., a desire to serve the public and a desire for career advancement), current job characteristics (e.g., number of employees supervised), and current workplace perceptions (e.g., client satisfaction, red tape) that are significantly related to high levels of organizational confidence. 
In light of the question we asked at the outset of this paper - how public sector organizations may go about populating their ranks with workers who harbor highly positive attitudes towards and perceptions of their organizations - perhaps the results of this analysis can inform the ways in which public organizations investigate for managerial traits that are easily detected, even prior to hiring. For example, the levels of desire to serve the public and for career advancement show a positive correlation with the highly positive government worker or High Organizational Confidence - i.e., respondents agreeing strongly with all items included in the organizational confidence scale. Additionally, public organizations might consider ways to nurture and grow organizational confidence. For example, this analysis indicates that increased perceptions of organizational red tape are directly but negatively related to High Organizational Confidence. Working toward reducing red tape, or at least managers’ perceptions thereof, might improve organizational confidence. Similarly, increasing client satisfaction might help to increase organizational confidence - or vice versa.

Unfortunately, because this research utilizes cross-sectional data, the analysis tests for relationships and associations, not causation. While we have established correlations with confidence and elements of our model conform to established causal directions from the literature, our full model is suggestive rather than conclusive. The current model does not enable us to make management recommendations asserting causal directions between the independent variables and organizational confidence. Organizational confidence may be reflective of discrete personal values that are perceived to be fulfilled by one’s public employer; or, it may be the case that some workers, perhaps with a high desire to serve the public, simply are more inclined to interpret their organizations' processes, activities, 
and outcomes as highly positive, no matter their value content. While this difficulty in interpretation is a concern, our goal in this paper is not to make causal claims regarding antecedents to organizational confidence, but rather to characterize the highly positive government worker by identifying attributes that correlate with the highest possible score on our organizational confidence scale.

Another finding for worker attributes that are perhaps easily detected by organizations is for the number of employees supervised, which correlated positively with High Organizational Confidence. Though we did not have any formal expectations for this variable, it may be the case that public managers with increased responsibilities (with the number of employees supervised as a proxy for responsibility) have greater understanding of the operations and outputs of their organizations, and therefore may be more qualified to readily perceive high quality service provision and high ethical standards if and when these occur. Or, due to the greater responsibility (and attendant time and energy investment) that comes with managing more workers, these respondents may simply have greater buy-in to the organization and its goals and mission and thus may be more likely to have High Organizational Confidence regardless of whether or not their organizations actually provide high quality services and have high ethical standards.

This brings up another weakness in our analysis: the lack of organization-level data related to performance. After all, one of the key determinants of organizational confidence may be organizational performance. The individual-level measure for respondent perception of client satisfaction provides a control for organizational performance (albeit an indirect one). While future inquiries should include organizational 
performance data, there will still remain individual-level factors that act as reference points (e.g., in the case of varying career histories, motives) for perceptions of organizations, no matter how well or poorly the organization performs.

The regression results also confirmed the contextual component of the framework, demonstrating that factors such as state can also affect positive attitudes towards and perceptions of one's organization. We find that respondents in Georgia are significantly more likely to report High Organizational Confidence than respondents in Illinois. However, perhaps more than the other findings this variable should be interpreted cautiously. Though tempting to draw conclusions related to Georgia's somewhat recent personnel administration reforms (e.g., pay-for-performance), the binary variable is blunt and encompasses all fixed state effects, not just those related to a particular policy change; moreover, we know from more careful analysis of personnel administration reforms in Georgia that the impacts have been mixed (Kellough and Nigro 2002).

Also requiring comment are some of the specific differences across the results for the analyses using the organizational confidence scale (measuring incremental changes in organizational confidence) and the High Organizational Confidence construct (indicating when a respondent strongly agreed with all scale items). Most notable, security motivation showed a significant and positive relationship with the scale operationalization, but not with the logit model predicting the binary variable, High Organizational Confidence. Although inconsistent across the analyses, one explanation may be that the security motivation construct is a relatively extrinsic or "hygienic" work motive, of which generally correlate with incremental increases in worker affectations, up 30 
to a point, but not with relatively high affectations for work or organizations (Herzberg 1968). However, this is speculative and we acknowledge that this part of the analysis raises questions that cannot be addressed readily with the current data. Another notable difference across the analyses is for absenteeism. Increases in days of work missed decreases the likelihood of reporting High Organizational Confidence, but has no significant effect on the organizational confidence scale. One explanation for the lack of consistency may be that managers with High Organizational Confidence are simply less likely to miss work. The last inconsistency of note across the findings is for organizational size. While size negatively and significantly affected the organizational confidence scale, it had no statistically significant effect on the likelihood of reporting High Organizational Confidence. It is possible that this difference is explained in the same way as the other inconsistencies and the general expectation that motivated this study - that workers with highly positive attitudes towards work and work environment are different than their less-enthused colleagues. However, organizational size is not wellknown for its predictive consistency. ${ }^{8}$

There are further limitations of this study in addition to those mentioned above related to cross-sectional analysis and organizational performance data. Because this research analyzes data from a sample of government employees in two states, the results are not generalizable to the nation. Next, the research utilized perceptual data gathered through a survey. As with all survey research, we run the risk of "common source bias"

\footnotetext{
8 Hall and Tolbert (2005) and others (Argyris 1972, Aldrich 1971) suggest that the analysis of organizational size must accompany the investigation of other organizational characteristics and additional factors, given the inconsistency and unreliability of findings regarding size as an antecedent variable in organizational studies.
} 
(Campbell and Fiske 1959). While this certainly is reason for concern, for studies implementing survey items measuring perceptions we feel the risk of potential bias (in the instance of this paper, not generally) relatively small. While it is possible that respondent perceptions may be untrue, unrealistic, or inconsistent, research indicates that perceptions play an important role in driving individual actions, relationships, and behavior (Buckley and Chapman 1997; Lord and Maher 1993; O’Connor, Bord and Fisher 1999). Moreover, the data include responses from only $43 \%$ of all managers surveyed, thus it is possible that those who responded to the survey are more likely to report overall positive perceptions of their organizations, though it is equally likely that the respondents are motivated by a desire to vent their frustration and unhappiness with their employers. Last, all responses to the survey are retrospective and require respondents to recall job history information, though research indicates that respondents accurately recall their employment history (Dex 1991).

The value of this study is that it tests High Organizational Confidence, a multidimensional concept of the highly positive government worker. The concept draws partly on the familiar affectation commitment, specifically having a sense of pride in one's organization, and includes items for which the referent is the organization, rather than the individual, and for which the item themes or foci are perceptions of organizational outcomes and operations, rather than internal or psychological states. The convergence of the perception of high quality service provision and high ethical standards by an organization with high reported levels of personal pride in the same organization represents a novel combination of affective and expectancy elements of worker attitudes and values that require attention given the increasing diversity in career experiences and 32 
background and training of the public service (Light 1999). In recent history the public sector has faced challenges in recruiting and retaining talented employees (Abramson and Gardner 2002; Partnership for Public Service 2002), making understanding of the factors that shape loyalty and positive perceptions of employing organizations imperative.

Future research can help to strengthen the concept of organizational confidence. The findings presented here merely touch on a complicated phenomenon. There are numerous important factors that we fail to capture, but which warrant future research. Most obvious, studies with larger samples and using time series data will better enable researchers to understand the ways in which perceptions or organizational efficacy and ethicalness vary over time and the causal mechanisms that determine increases and decreases in organizational confidence. We hope that this paper inspires future research in the more positive aspects of public sector work. 


\section{References}

Abramson, Mark A., and Nicole Willenz Gardner. (Eds.). 2002. Human Capital 2002. The PricewaterhouseCoopers Endowment for The Business of Government. Lanham, MD: Rowman \& Littlefield Publishers.

Aldrich, H.E. (1971) "Technology and Organizational Structure: A Reexamination of the Findings of the Aston Group.” Administrative Science Quarterly 17, p. 26-43.

Alonso, P. and G. B. Lewis. 2001. Public Service Motivation and Job Performance. American Review of Public Administration 31(4):363-380.

Amos, Elizabeth and Bart Weathington. 2008. An Analysis of the Relation Between Employee-Organization Value Congruence and Employee Attitudes. The Journal of Psychology 142(6):615-631.

Argyris, C. (1972) The Applicability of Organizational Sociology. London: Cambridge University Press.

Azjen, I. 2000. Nature and operations of attitudes. Annual Review of Psychology 52:2758.

Behn, Robert D. 2001. Rethinking Democratic Accountability. Washington DC: Brookings Institution.

Boardman, Craig, Barry Bozeman, and Branco Ponomariov. 2010. Private sector imprinting: an examination of the impacts of private sector job experience on public managers' work attitudes. Public Administration Review.

Boardman, Craig, and Eric Sundquist. 2009. Toward understanding work motivation: worker attitudes and the perception of effective public service. American Review of Public Administration Advance draft available online.

Bozeman, Barry, and Hal Rainey. 1998. Organizational rules and bureaucratic personality. American Journal of Political Science 42:163-189.

Brehm, J. and S. Gates (1999) Working, shirking, and sabotage. Ann Arbor: Univ. Michigan Press.

Bretschneider, Stu. 1990. Management information systems in public and private organizations: An Empirical Test. Public Administration Review 50 (5): 536-545.

Brewer, Gene and Richard Walker. 2009. The Impact of Red Tape on Governmental Performance: An Empirical Analysis. Journal of Public Administration Research 
and Theory Advance Access published online on February 18, 2009 Journal of Public Administration Research and Theory, doi:10.1093/jopart/mun040

Brewer, Gene and Sally C. Selden. 1998. Whistle Blowers in the Federal Civil Service: New Evidence of the Public Service Ethic. Journal of Public Administration Research and Theory 8(3): 413-439.

Brooke, Paul P. and James L. Price. 1989. The determinants of employee absenteeism: An empirical test of a causal model. Journal of Occupational Psychology 62(1):1-19.

Buchanan, Bruce. 1974. Government managers, business executives, and organizational commitment. Public Administration Review 35:339-347.

Buckley, Peter J., and Malcolm Chapman. 1997. The perception and measurement of transaction costs. Cambridge Journal of Economics 21(2):127-145.

Campbell, Donald Thomas and Donald W. Fiske. 1959. Convergent and discriminant validation by the multitrait-multimethod matrix. Psychological Bulletin 56: 81105.

Cohen, Aaron. 1996. "On the discriminant validity of the Meyer-Allen measure of organizational commitment. How does it fit with the work commitment construct?” Educational and Psychological Measurement 56(3): 494-503.

Cohen, Aaron. 2007. Commitment before and after: An evaluation and reconceptualization of organizational commitment. Human Resources Management Review 17:336-354.

Crewson, Phillip E. 1997. Public-Service Motivation: Building Empirical Evidence of Incidence and Effect. Journal of Public Administration Research and Theory 7 (4):499-518.

DeHart-Davis, L. and Sanjay K. Pandey. 2005. Red tape and public employees: Does perceived rule dysfunction alienate managers? Journal of Public Administration Research and Theory 15(1):133-148.

DeHart-Davis, Leisha. 2008. Green tape: A theory of effective organizational rules. Journal of Public Administration Research and Theory Advance Access published February 25, 2008.

Dewitt, R.L., L.K. Trevino, and K.A. Mollica (2003) "Stuck in the middle: a controlbased model of managers' reactions to their subordinates' layoffs.” Journal of Managerial Issues 15(1), p. 32-49. 
Dex, Shirley. (ED.). 1991. Life and work history analyses: qualitative and quantitative developments. London and New York: Rouledge.

Dougherty, Michael J. 2000. The cost of being ethical. Global Virtue Ethics Review 2(3):217-239.

Eggleston, K., and Zeckhauser, R. 2002. Government contracting for health care. In J. D. Donahue and J. S. Nye, Jr. (Eds.), Market-based governance (pp. 29-65). Washington, DC: Brookings Institution Press.

Feeney, Mary K. 2008. Sector perceptions among state-level public managers. Journal of Public Administration Research and Theory 18(3):465-494.

Feeney, Mary K., and Hal G. Rainey. 2009. Journal of Public Administration Research and Theory Advance Access published online on November 10, 2009 Journal of Public Administration Research and Theory, doi:10.1093/jopart/mup027.

Fishbein, Martin, and Susan. Middlestadt. 1995. Noncognitive effects on Attitude Formation and Change: Fact or Artifact? Journal of Consumer Psychology 6, 107115.

Goodsell. Charles T. 2004. The Case for Bureaucracy: A Public Administration Polemic, 4th Edition. Washington DC: CQ Press.

Graaf, Gjalt de and Zeger van der Wal. 2008. On value differences experienced by sector switchers. Administration \& Society 40 (1):79-103.

Hall, R.H. and P.S. Tolbert (2005) Organizations: Structures, Processes, and Outcomes. ( $9^{\text {th }}$ Edition). Upper Saddle River, New Jersey: Prentice Hall.

Jansen, Karen J. and Amy Kristof-Brown (2006) “Toward a Multidimensional Theory of Person-Environment Fit” Journal of Managerial Issues 18(2)

Jensen, Michael C. 1998. Foundations of Organizational Strategy. Cambridge, MA: Harvard University Press.

Kanuk, Leslie and Conrad Berenson. 1975. Mail surveys and response rates: a literature review. Journal of Marketing Research 12:440-453.

Kellough, J. Edward, and Lloyd G. Nigro. 2006. Dramatic Reform in the Public Service: At-Will Employment and the Creation of a New Public Workforce. Journal of Public Administration Research and Theory, 16(3): 447-466.

Kristof, Amy L. 1996. Person-organization fit: An integrative review of its conceptualizations, measurement, and implications. Personnel Psychology, 49(1): $1-49$. 
Light, Paul. 1999. The New Public Service. Washington DC: Brookings Institute Press.

Lord, Robert G., and Karen J. Maher. 1993. Leadership and information processing: Linking perceptions and performance. London: Routledge.

Marsden, Peter, Cynthia Cook, and David Knoke.1994. Measuring Organizational Structures and Environments. American Behavioral Scientist 37(7) 891-910.

Meglino, B.M., E.C. Ravlin, and C.L. Adkins (1989) “A work values approach to corporate culture: a field test of the value congruence process and its relationship to individual outcomes.” Journal of Applied Psychology 74: 424-432.

Merton, Robert. 1940. Bureaucratic structure and personality. Social Forces 18:560-568.

Meyer, P.J. and J.N. Allen (1984) “Testing the side bet theory of organizational commitment: some methodological considerations.” Journal of Applied Psychology 67: 372-378.

Naff, Katherine C., and John Crum. 1999. Working for America: does public service motivation make a difference? Review of Public Personnel Administration 19(4): 5-16.

Nagy, M. (2002). Using a single-item approach to measure facet satisfaction. Journal of Occupational and Organizational Psychology, 75(1), 77-86.

Nigro, Lloyd G. and J. Edward Kellough. 2000. Civil Service Reform in Georgia Going to the Edge? Review of Public Personnel Administration, 20(4):41-54.

Niskanen, William A. 1973. Bureaucracy: Servant or master? London: Institute for Economic Affairs.

O’Connor, Robert E., Bord, Richard J., and Fisher, Ann. 1999. Risk perceptions, general environmental beliefs, and willingness to address climate change. Risk Analysis 19(3): 461-471.

Pandey, Sanjay K., Coursey, David H., and Donald P. Moynihan. 2007. Organizational effectiveness and bureaucratic red tape: A multimethod study. Public Performance and Management Review 30(3): 398-425.

Pandey, Sanjay K., and Gordon Kingsley. 2000. Examining red tape in public and private organizations: Alternative explanations from a social psychological model. Journal of Public Administration Research and Theory 10:779-800. 
Pandey, Sanjay K., and Eric W. Welch. 2005. Beyond stereotypes: A multistage model of managerial perceptions of red tape. Administration \& Society 37(5): 542.

Park, S.M. and Hal G. Rainey (2007) “Antecedents, mediators, and consequences of affective, normative, and continuance commitment.” Review of Public Personnel Administration 27(3), p. 197-226.

Partnership for Public Service. 2002. Mid-Career Hiring in the Federal Government: A Strategy for Change. Washington DC.

Perry, James L. 1996. Measuring public service motivation: an assessment of construct reliability and validity. Journal of Public Administration Research and Theory 6 (1): 5-12.

Perry, James L. and Hal G. Rainey. 1988. The public-private distinction in organization theory - A critique and research strategy. Academy of Management Review 13(2): 182-201.

Perry, James L., and Lois Recascino Wise. 1990. The motivational bases of public service. Public Administration Review 50(3): 367-373.

Petty, Richard E. and Jon A. Krosnick (Eds.) 1995. Attitude Strength: Antecedents and Consequences, Vol. 4 Ohio State University Series on Attitudes and Persuasion. Mahwah: Erlbaum.

Pfeffer, Jeffrey. 1998. The human equation: Building profits by putting people first. Cambridge, MA: Harvard Business School Press.

Porter, Lyman W., Richard M. Steers, Richard T. Mowday and Paul V. Boulian (1974) "Organizational Commitment, Job Satisfaction, and Turnover Among Psychiatric Technicians,” Journal of Applied Psychology, 59, 603-609.

Rainey, Hal. G. 1982. Reward preferences among public and private managers: In search of the service ethic. American Review of Public Administration 16(4), 288.

Rainey, Hal. G. 1983. Public agencies and private firms: Incentive structures, goals and individual roles. Administration \& Society 15(2): 207-242.

Rainey, Hal G. and P. Steinbauer. 1999. Galloping Elephants: Developing Elements of a Theory of Effective Government Organizations. Journal of Public Administration Research and Theory 9(1):1-32.

Rawls, James, Robert Ullrich, and Oscar Nelson. 1975. A comparison of managers entering or re-entering the profit and non-profit sectors. Academy of Management Journal September. 
Rotolo, Thomas, and John Wilson. 2006. Employment sector and volunteering: Contribution of Nonprofit and Public Sector Workers to the Volunteer Labor Force. The Sociological Quarterly 47:21-40.

Schneider, Benjamin. 1987. The people make the place. Personnel Psychology 40:43756.

Schneider, Benjamin, Harold W. Goldstein, and D. Brent Smith. 1995. The ASA framework: An update. Personnel Psychology 48:747-73.

Scott, Patrick G., and Sanjay K. Pandey. 2000. The influence of red tape on bureaucratic behavior: an experimental simulation. Journal of Policy Analysis and Management 19(4): 615-633.

Simon, Herbert. 1997. Administrative behavior: A study of decision-making processes in administrative organizations (5th ed.). New York: Macmillan.

Sjoberg, Gideon, Richard A. Brymer, and Buford Farris. 1966. Bureaucracy and the lower class. Sociology and Social Research 50:325-337.

Sousa-Poza, Alfonso, and Fred Henneberger. 2004. Analyzing job mobility with job turnover Intentions: An international comparative study. Journal of Economic Issues 38:113-136.

Spencer, Daniel G. and Steers, Richard M. 1980. The influence of personal factors and perceived work experiences on employee turnover and absenteeism. Academy of Management Journal 21(4): 245-50.

Steers, Richard M. and Rhodes, Susan R. 1978. Major influences on employee attendance: A process model. Journal of Applied Psychology 63(4):391-407.

Taylor, Jeannette. 2008. Organizational Influences, Public Service Motivation and Work Outcomes, International Public Management Journal, 11(1):67-88.

Vandenheuvel, Audrey. 1993. When roles overlap, workers with family responsibilities. Australian Institute of Family Studies. Monograph no.14, Melbourne.

Vandenheuvel, Audrey. 1994. Public and private sector absence: Does it differ? Journal of Industrial Relations 36(4): 530-545.

Welch, Eric W., and Sanjay K. Pandey. 2007. E-government and bureaucracy: Toward a better understanding of intranet implementation and its effect on red tape. Journal of Public Administration Research and Theory 17:379-404. 
Wilson, James Q. 1989. Bureaucracy: What government agencies do and why they do it. New York: Basic Books.

Wooden, Mark. 1990. The 'Sickie': A Public Sector Phenomenon? Journal of Industrial Relations, 32(4):560-576.

Wooden, Mark. 1992. The cost of time off work in Australia. Asia Pacific Journal of Human Resources 39(3):1-10.

Wright, Bradley E. 2001. Public Sector Work Motivation: A Review of the Current Literature and a Revised Conceptual Model. Journal of Public Administration Research and Theory 11(4):559-586.

Wright, Bradley E. and Sanjay Pandey. 2009. Transformational Leadership in the Public Sector: Does Structure Matter? Journal of Public Administration Research and Theory Advance Access published online on April 30, 2009, doi:10.1093/jopart/mup003 
Table 1. Factor Analysis: Organizational Confidence

\begin{tabular}{lr}
\hline & $\begin{array}{c}\text { Organizational } \\
\text { Confidence }\end{array}$ \\
\hline I feel a sense of pride working for this organization & .862 \\
This organization has high ethical standards & .860 \\
I would rate the overall quality of work being done in my & .840 \\
organization as very good & 72.937 \\
\hline \% Variance Explained & 2.188 \\
\hline Eigenvalue & \\
\hline Extraction Method: Principal Component Analysis. & \\
\hline Dimensions represent $72.937 \%$ of the common variance in the initial correlation matrix
\end{tabular}


Table 2. Scale Reliability for the Dependent Variable: Organizational Confidence

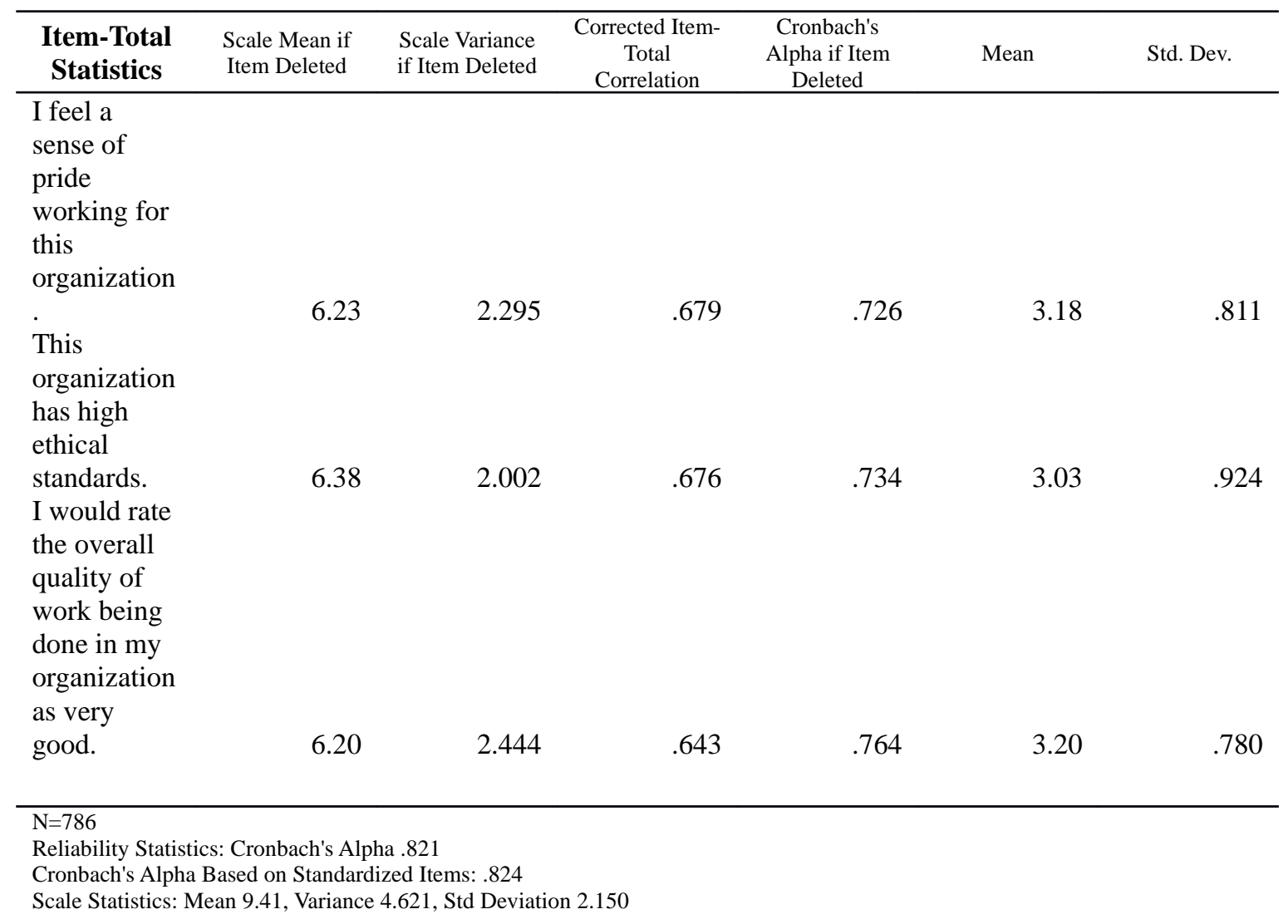


Table 3. Factor Analysis Work Motivation Items

\begin{tabular}{lrr}
\hline & Securit & \\
& $\mathbf{y}$ & Advancement \\
\hline Opportunity for advancement within the organization's hierarchy & .255 & $\mathbf{. 7 6 8}$ \\
Job Security & .773 & .043 \\
The organization's pension or retirement plan & $\mathbf{. 8 1 7}$ & .176 \\
Desire for increased responsibility & -.010 & $\mathbf{. 8 5 1}$ \\
Benefits (medical, insurance) &. $\mathbf{8 4 4}$ & .149 \\
Few, if any, alternative job offers & .377 & -.290 \\
\hline \% Variance Explained & 36.390 & 60.606 \\
Eigenvalue & 2.346 & 1.290 \\
\hline
\end{tabular}

Extraction Method: Principal Component Analysis.

Rotation Method: Varimax with Kaiser Normalization.

Rotation converged in 3 iterations. 
Table 4. Difference of Means Tests for High Organizational Confidence

\begin{tabular}{|c|c|c|c|c|c|c|}
\hline Variable & & $\mathbf{N}$ & Mean & Std. Dev. & $\mathbf{F}$ & Sig. \\
\hline Public Service & All Else & 619 & 0.82 & 0.39 & 17.34 & 0.000 \\
\hline Motivation & High Org Confidence & 158 & 0.92 & 0.27 & & \\
\hline \multirow{2}{*}{ Client Satisfaction } & All Else & 615 & 2.72 & 0.74 & 92.65 & 0.000 \\
\hline & High Org Confidence & 156 & 3.35 & 0.63 & & \\
\hline \multirow{2}{*}{ Red Tape } & All Else & 615 & 7.38 & 1.93 & 75.47 & 0.000 \\
\hline & High Org Confidence & 156 & 5.81 & 2.30 & & \\
\hline \multirow{2}{*}{ Security Motivation } & All Else & 609 & 0.01 & 1.01 & 0.61 & 0.434 \\
\hline & High Org Confidence & 155 & -0.06 & 0.97 & & \\
\hline \multirow{2}{*}{$\begin{array}{l}\text { Career Advancement } \\
\text { Motivation }\end{array}$} & All Else & 609 & -0.05 & 1.00 & 10.28 & 0.001 \\
\hline & High Org Confidence & 155 & 0.23 & 0.96 & & \\
\hline \multirow{2}{*}{ Private Experience } & All Else & 546 & 0.29 & 0.46 & 0.58 & 0.446 \\
\hline & High Org Confidence & 142 & 0.26 & 0.44 & & \\
\hline \multirow{2}{*}{ \#Employees Supervised } & All Else & 530 & 1.84 & 1.32 & 6.19 & 0.013 \\
\hline & High Org Confidence & 134 & 2.16 & 1.37 & & \\
\hline \multirow{2}{*}{ Absenteeism } & All Else & 624 & 21.06 & 16.45 & 9.54 & 0.002 \\
\hline & High Org Confidence & 161 & 16.89 & 9.46 & & \\
\hline \multirow{2}{*}{ Age } & All Else & 619 & 48.82 & 8.59 & 1.66 & 0.198 \\
\hline & High Org Confidence & 159 & 49.81 & 8.50 & & \\
\hline \multirow{2}{*}{ Age Squared } & All Else & 619 & 2457.38 & 820.92 & 1.67 & 0.197 \\
\hline & High Org Confidence & 159 & 2552.40 & 851.54 & & \\
\hline \multirow{2}{*}{ Private to Public } & All Else & 622 & 0.13 & 0.33 & 1.22 & 0.271 \\
\hline & High Org Confidence & 160 & 0.09 & 0.29 & & \\
\hline \multirow{2}{*}{ Georgia } & All Else & 625 & 0.50 & 0.50 & 37.02 & 0.000 \\
\hline & High Org Confidence & 161 & 0.76 & 0.43 & & \\
\hline \multirow{2}{*}{ Org Age } & All Else & 571 & 55.37 & 38.41 & 4.97 & 0.026 \\
\hline & High Org Confidence & 149 & 63.14 & 35.98 & & \\
\hline \multirow{2}{*}{ Org Size (FTE) } & All Else & 596 & 5264.69 & 6284.24 & 0.14 & 0.705 \\
\hline & High Org Confidence & 152 & 5046.71 & 6485.53 & & \\
\hline
\end{tabular}


Table 5. OLS Model - Extracted Factor Score for Organizational Confidence

\begin{tabular}{|c|c|c|c|c|}
\hline & $\begin{array}{c}\text { Unstand. } \\
\text { Coeff. }\end{array}$ & $\begin{array}{l}\text { Std. } \\
\text { Error }\end{array}$ & $\begin{array}{c}\text { Stand. } \\
\text { Coeff. } \\
\text { Beta } \\
\end{array}$ & \\
\hline Constant & -1.718 & 0.769 & & \\
\hline Desire to Serve the Public & 0.248 & 0.082 & 0.092 & $* * *$ \\
\hline Red Tape & -0.106 & 0.015 & -0.227 & $* * *$ \\
\hline Client Satisfaction & 0.493 & 0.041 & 0.382 & $* * *$ \\
\hline Private Experience & -0.033 & 0.074 & -0.015 & \\
\hline Private to Public & 0.043 & 0.099 & 0.014 & \\
\hline Absenteeism & -0.002 & 0.002 & -0.035 & \\
\hline Security Motivation & 0.054 & 0.030 & 0.054 & $*$ \\
\hline Career Advancement Motivation & 0.145 & 0.031 & 0.145 & $* * *$ \\
\hline \#Employees Supervised & 0.065 & 0.020 & 0.094 & $* * *$ \\
\hline Georgia & 0.273 & 0.065 & 0.137 & $* * *$ \\
\hline Age & 0.020 & 0.031 & 0.169 & \\
\hline Age Squared & 0.000 & 0.000 & -0.117 & \\
\hline Org Age & 0.001 & 0.001 & 0.030 & \\
\hline Org Size (FTE) & 0.000 & 0.000 & -0.057 & $*$ \\
\hline $\begin{array}{l}\mathrm{P}<.10==^{*}, \mathrm{p}<.05=^{* *}, \mathrm{p}<.01=^{* * *} \\
\mathrm{~N}=732 \\
\mathrm{R} 0.628 \\
\mathrm{R}^{2} 0.395 \\
\text { Adjusted } \mathrm{R}^{2} 0.383 \\
\text { Std. Error of the Estimate } 0.778\end{array}$ & & & & \\
\hline
\end{tabular}


Table 6. Logit: Probability that a Respondent Has a High Level of Organizational Confidence

\begin{tabular}{lrrrl} 
& \multicolumn{1}{c}{ B } & \multicolumn{1}{l}{ S.E. } & Exp(B) & \\
\hline Desire to Serve the Public & $\mathbf{0 . 7 5 3}$ & $\mathbf{0 . 3 6 9}$ & $\mathbf{2 . 1 2 4}$ & $* *$ \\
Red Tape & $\mathbf{- 0 . 2 4 9}$ & $\mathbf{0 . 0 5 1}$ & $\mathbf{0 . 7 8 0}$ & $* * *$ \\
Client Satisfaction & $\mathbf{1 . 2 6 5}$ & $\mathbf{0 . 1 8 5}$ & $\mathbf{3 . 5 4 4}$ & $* * *$ \\
Private Experience & -0.330 & 0.280 & 0.719 & \\
Private to Public & -0.288 & 0.394 & 0.750 & \\
Absenteeism & $\mathbf{- 0 . 0 2 0}$ & $\mathbf{0 . 0 0 9}$ & $\mathbf{0 . 9 8 0}$ & $* *$ \\
Security Motivation & -0.105 & 0.113 & 0.901 & \\
Career Advancement Motivation & $\mathbf{0 . 1 9 9}$ & $\mathbf{0 . 1 1 5}$ & $\mathbf{1 . 2 2 1}$ & $*$ \\
\#Employees Supervised & $\mathbf{0 . 1 5 6}$ & $\mathbf{0 . 0 7 8}$ & $\mathbf{1 . 1 6 9}$ & $* *$ \\
Georgia & $\mathbf{0 . 7 8 8}$ & $\mathbf{0 . 2 5 1}$ & $\mathbf{2 . 2 0 0}$ & $* * *$ \\
Age & 0.114 & 0.111 & 1.121 & \\
Age Squared & -0.001 & 0.001 & 0.999 & \\
Org Age & 0.000 & 0.003 & 1.000 & \\
Org Size (FTE) & 0.000 & 0.000 & 1.000 & \\
Constant & -7.544 & 2.858 & 0.001 & \\
\hline
\end{tabular}

$\mathrm{P}<.10=^{*}, \mathrm{p}<.05=^{* *}, \mathrm{p}<.01=^{* * *}$

$\mathrm{N}=732$

Chi ${ }^{2}$ 168.98; Sig. 0.000

-2 Log likelihood 568.02

Cox \& Snell $\mathrm{R}^{2} 0.21$

Nagelkerke $\mathrm{R}^{2} 0.32$ 


\section{Appendix $1 \quad$ NASP-III Approach}

The National Administration Studies Project (NASP) aims to increase our empirical knowledge of public management and administration. NASP-III is an attempt to blend the goals of NASP-I and II while addressing a few new themes of its own. NASP-III collected data on public and nonprofit managers in Georgia and Illinois. Unlike NASP-II, which focused on a single functional agency (health and human services), the NASP-III sample includes managers from agencies and organizations of numerous functions.

The population of managers in Georgia was drawn from the Georgia Department of Audits (DoA) comprehensive list of state employees who were on state agency payrolls during the fiscal year 2003/2004. We removed employees at technical colleges, commissions, authorities, the office of the governor, and institutions from the judicial or legislative branch. In addition we removed employees at institutions with less than 20 employees. The population included any job titles coded as "director" "coordinator" "officials or manager" and "professionals" under the pay grade of 017 and all individuals with a pay grade of 017 or higher. The resulting population included 6,164 Georgia managers.

The population of managers in Illinois was developed through a Freedom of Information Act request for a list of all state employees designated as either "senior public service administrators" or "public service administrators." This list included information on 5,461 state employees, including name, agency, and county.

\section{Survey Administration}

The survey administration included a pre-contact letter, Wave I survey with letter, followup postcard mailing, Wave II mailing, follow-up contacts by phone call and email, and a final Wave III mailing. The survey was closed January 1, 2006. We received 549 responses in Wave I, 135 in Wave II, and 111 in Wave III.

\section{Response Rates}

Though we began with a sample of 2000 public sector respondents our sample was reduced to 1849 (912 Georgia, 937 Illinois) because of respondents who had retired (16 cases) or are longer working for the agency (135 cases). The survey was closed with 432 responses from Georgia and 358 from Illinois. 


\section{Appendix $2 \quad$ Descriptive Statistics}

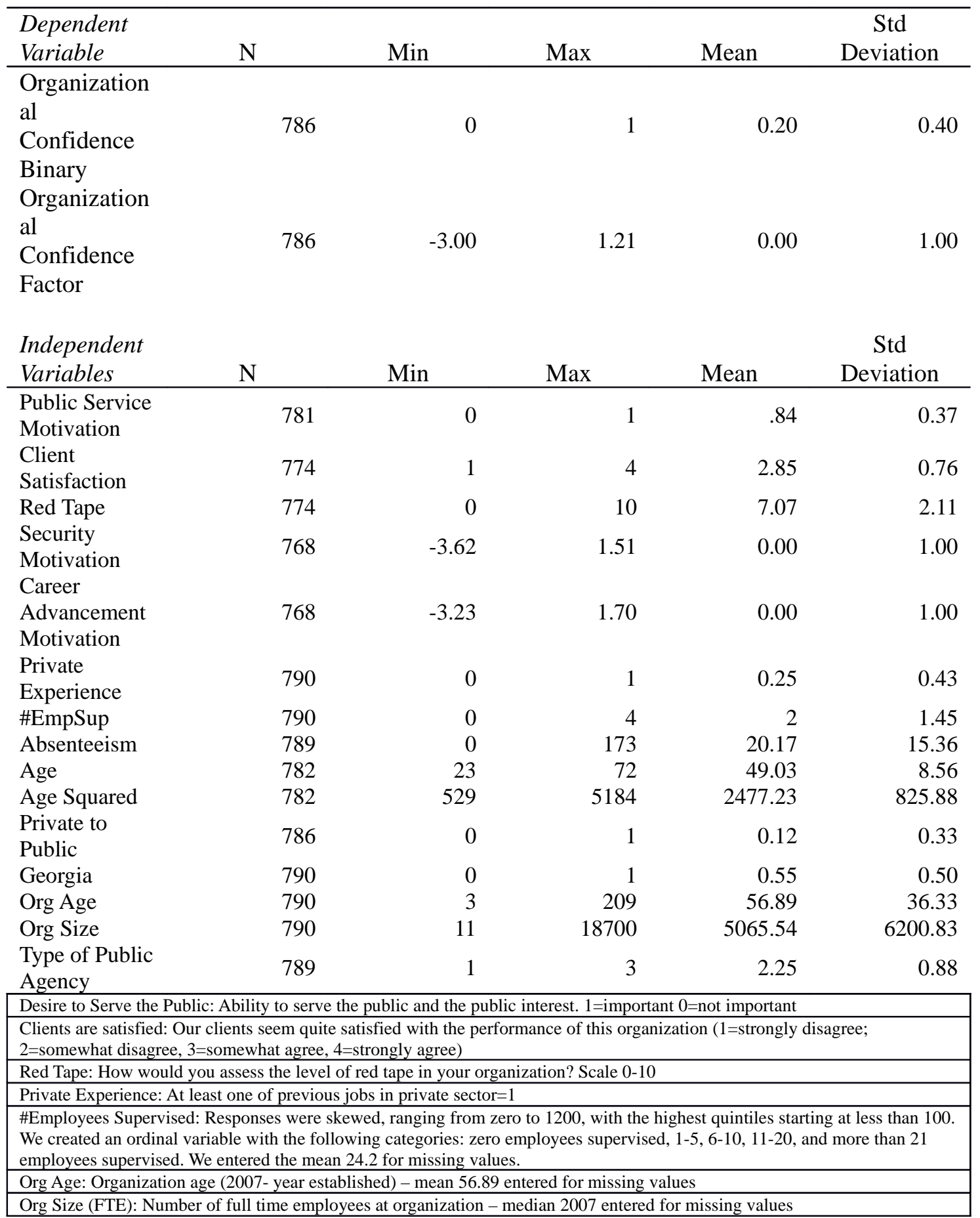




\section{Appendix $3 \quad$ Correlation Matrix}

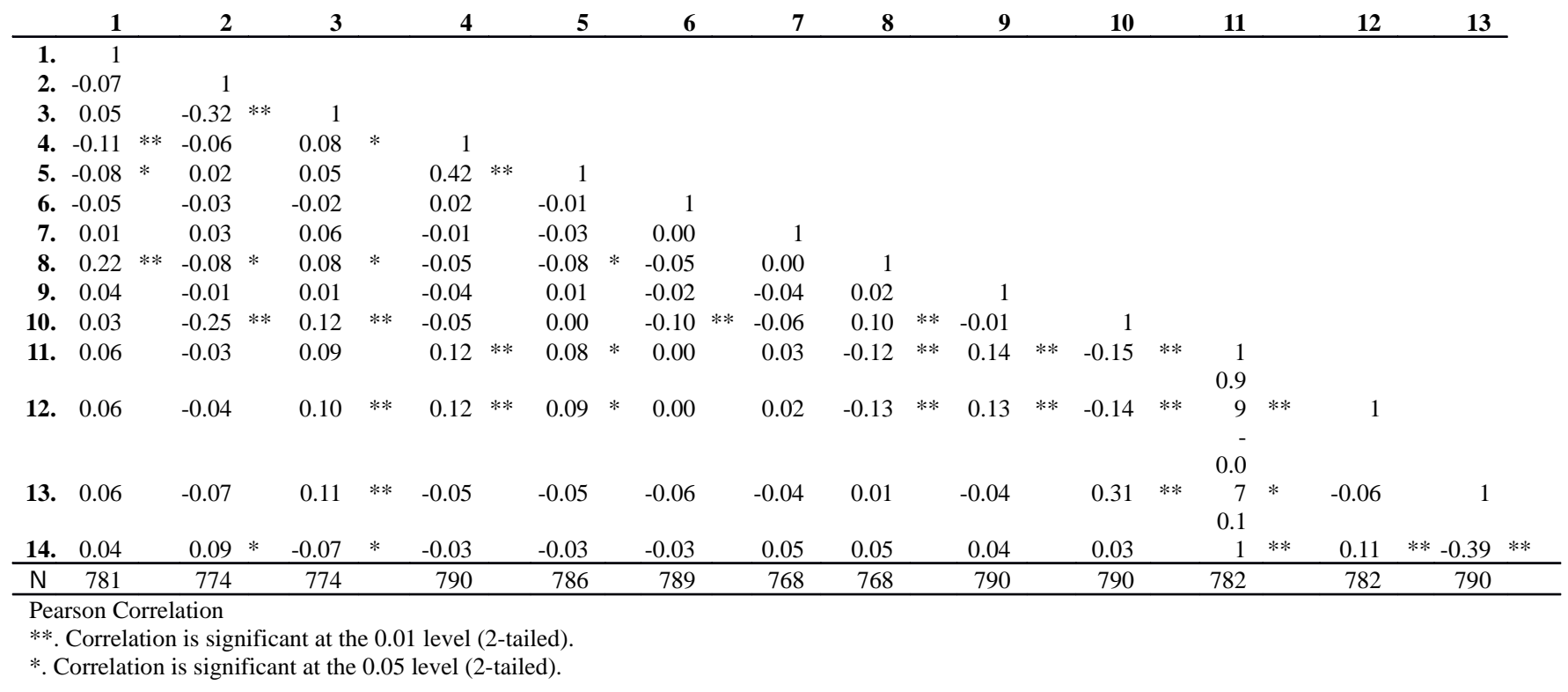

